Research Article

\title{
Evaluation of Volatile Compounds during the Fermentation Process of Yogurts by Streptococcus thermophilus Based on Odor Activity Value and Heat Map Analysis
}

\author{
Li Zhang, Si Mi, Ruo-bing Liu, Ya-xin Sang, and Xiang-hong Wang \\ Department of Food Science and Technology, Hebei Agricultural University, Baoding 07001, China \\ Correspondence should be addressed to Xiang-hong Wang; wangxianghong73@sina.com
}

Received 11 January 2020; Revised 19 May 2020; Accepted 23 June 2020; Published 13 July 2020

Academic Editor: Pavel Nesterenko

Copyright (C) 2020 Li Zhang et al. This is an open access article distributed under the Creative Commons Attribution License, which permits unrestricted use, distribution, and reproduction in any medium, provided the original work is properly cited.

\begin{abstract}
The volatile composition of yogurt produced by Streptococcus thermophilus fermentation at different time points was investigated by gas chromatography-mass spectrometry combined with simultaneous distillation and extraction. A total of 53 volatile compounds including 11 aldehydes, 10 ketones, 8 acids, 7 benzene derivatives, 13 hydrocarbons, and 4 other compounds were identified in all of the samples. Ketones and hydrocarbons were the predominant volatile components in the early stage, whereas acids were the predominant volatiles in the late stage. The importance of each volatile was evaluated based on odor, threshold, and odor activity values (OAVs). Twenty-nine volatiles were found to be odor-active compounds (OAV > 1), among which (E, E)-2,4decadienal had the highest OAV (14623-22278). Other aldehydes and ketones such as octanal, dodecanal, 2-nonen-4-one, and 2undecanone also showed high odor intensity during fermentation. Heat map analysis was employed to evaluate the differences during fermentation. The results demonstrated that the volatile profile based on the content and OAVs of volatile compounds enables the good differentiation of yogurt during fermentation.
\end{abstract}

\section{Introduction}

Yogurt is a very popular fermented milk product that is widely consumed fermented milk product worldwide. Its unique sensory, odor, and texture qualities are formed during the process of microbial fermentation [1]. Of them, odor is one of the most important factors that determines the acceptability and preference of yogurts. More than 100 volatiles including carbonyl compounds, alcohols, acids, esters, hydrocarbons, aromatic compounds, sulfur-containing compounds, and heterocyclic compounds were detected in yogurt at low to trace concentrations [2-4].

Yogurt is usually produced using a mixture of homofermentative lactic acid bacteria such as Streptococcus thermophilus and Lactobacillus bulgaricus as the starter culture $[5,6]$. A large number of studies have been conducted on the factors that affect the flavor of yogurt such as the source of milk [7-9], milk components $[6,10]$, starter cultures [11], process technology $[12,13]$, additives [14], and storage conditions $[9,11]$. Among them, the starter cultures play a key role in the formation of flavor compounds. The difference in aroma has been attributed to the presence of different bacteria, so an increasing amount of attention has been paid to the influence of single bacteria on the flavor of yogurt. Imhof et al. (1995) reported that volatile organic compounds are produced by Thermophilic lactobacilli and Mesophilic lactococci single strain dairy starter and considered 2,3-butanedione, 2,3-pentanedione, dimethyl sulfide, and benzaldehyde to be differential compounds formed by different strains [15]. Wang et al. (2015) isolated the L. lactis strain from Tibetan kefir grains, which was used for yogurt making, and 25 types of flavor compounds including acetaldehyde, diacetyl, and 2-heptanone were generated [16].

S. thermophilus is an important bacterial strain used for the industrial production of yogurt, and it has an important influence on the odor quality of yogurt. Fermentation is an important step in yogurt processing and is a crucial step for the formation of yogurt odor quality. Hence, the formation and change in volatile components when yogurt is fermented by $S$. 
thermophiles are also of great significance to the quality formation and processing control of yogurt [11]. However, few studies have focused on this question. In addition, it is worth paying attention to which volatile components contribute to odor quality during yogurt fermentation. The odor activity value (OAV) is an important method used to select key odor components. It has been widely introduced to choose impact odorants in dairy product such as milk $[17,18]$, milk power $[19,20]$, and cheese [21-23]. Tian et al. (2019) reported that odor characteristic components in yogurt are generated by $L$. plantarum fermentation using OAV and confirmed that diacetyl, 2-heptaone, and 2-nonanone are important odor components [24].

The objective of this study was to monitor the change of volatile compounds during the fermentation process of yogurts by $S$. thermophilus. To this end, simultaneous distillation and extraction (SDE) and gas chromatography-mass spectrometry (GC-MS) were utilized. The odor activity value of the identified volatiles was calculated to evaluate the contributions of compounds on the overall aroma of the investigated samples. The present work could facilitate a better understanding of volatile composition in a typical yogurt and can be expected to be used for the improvement of the yogurt quality.

\section{Materials and Methods}

2.1. Yogurt Preparation. Pasteurized full-fat milk obtained from a local factory (Hebei Sanyuan Food Co., Ltd, Hebei, China) was fortified with $6.0 \%$ sugar. Homogenization was performed at 5 pa pressure and heat treatment at $98^{\circ} \mathrm{C}$ for $15 \mathrm{~min}$. Then milk was immediately cooled to about $41^{\circ} \mathrm{C}$ in a water bath and inoculated with a starter culture of $S$. thermophilus S2 (Hebei Inatural Biotech Co., Ltd., Hebei, China). The prepared solution $(1000 \mathrm{~mL})$ was added to sterile pots, which then were hermetically sealed after which the solution was fermented at $41^{\circ} \mathrm{C}$ for $6 \mathrm{~h}$ (until pH 4.2 was reached). Samples were taken at $0,1.5,3.0,4.5$, and $6.0 \mathrm{~h}$ during fermentation. The collected yogurts were stored at $-24^{\circ} \mathrm{C}$ until subsequent analysis.

2.2. Extraction of Volatile Compounds. The volatile compounds of yogurt were extracted using simultaneous distillation and extraction (SDE) in a Likens-Nickerson apparatus. A mixture of $200 \mathrm{~g}$ sample and $2 \mathrm{~L}$ deionized water was placed in a $5 \mathrm{~L}$ flask and connected to a LikensNickerson apparatus. Aqueous 2,4,6-trimethyl-pyridine $\left(40 \mathrm{mg} \cdot \mathrm{kg}^{-1}\right)$ was added as an internal standard. Then a U-tube apparatus was filled with water. An additional $50 \mathrm{~mL}$ diethyl ether was added. An additional $10 \mathrm{~mL}$ diethyl ether was poured into a finger-shaped bottom flask. Both flasks (containing diethyl ether and yogurt mixture, respectively) were heated to boiling. The extraction time was $2 \mathrm{~h}$. After extraction, the distillate in the $100 \mathrm{~mL}$ flask was dried over anhydrous sodium sulfate ( $5 \mathrm{~g}$ ), concentrated using vacuum rotary evaporation, and then stored in headspace vials. Extraction of each sample was performed in triplicate.

2.3. GC-MS Analysis. The analysis of volatile compounds was conducted using the Agilent 6890 GC System equipped with the Agilent 5975 MS (Agilent Technologies, Santa Clara, CA, USA) and fitted with the DB-5 capillary column (30 m $\times 0.25 \mathrm{~mm}$ ID, $0.25 \mu \mathrm{m}$ film thickness; J\&W Scientific, Folsom, CA, USA). Ultrahigh purity helium ( $\geq 99.999 \%)$ was employed as the carrier gas with a constant flow rate of $1 \mathrm{~mL} \cdot \mathrm{min}^{-1}$, and $1 \mu \mathrm{l}$ extraction of sample was injected at $250^{\circ} \mathrm{C}$ in splitless mode. The oven temperature was programmed at $40^{\circ} \mathrm{C}$ for $2 \mathrm{~min}$ and then ramped to $220^{\circ} \mathrm{C}$ at a rate of $6{ }^{\circ} \mathrm{C} \cdot \mathrm{min}^{-1}$ and held at $220^{\circ} \mathrm{C}$ for $5 \mathrm{~min}$. The mass spectrometer was operated in the electron impact ionization mode at a voltage of $70 \mathrm{eV}$ and ion source temperature at $230^{\circ} \mathrm{C}$. Mass spectra were taken over an $\mathrm{m} / z$ range of $30-400$. Retention indices were calculated after analyzing $\mathrm{C}_{8}-\mathrm{C}_{20} n$ alkane series under the same chromatographic conditions.

2.4. Identification of Volatile Compounds. The volatile components were identified by comparing their mass spectra to mass spectra from mass spectral libraries (NIST 05, WILEY 7.0) and to previously published data. These volatiles were further confirmed by matching their linear retention indices (LRIs) and odor descriptions in the literature $[3,24,25]$. The LRIs were computed according to the following equation [26]:

$$
\mathrm{LRI}=100 \times\left(\frac{R t(i)-R t(n)}{R t(n+1)-R t(n)+n}\right),
$$

where $R t$ (i) is the retention time of the individual compound under investigation (i) and $R t(n)$ and $R t(n+1)$ refer to the retention times of $n$-alkanes $\left(\mathrm{C}_{8}-\mathrm{C}_{22}\right.$; Supelco Analytical, Sigma, St. Louis, MO, USA) that elute before and after the target compound (i) for the same chromatographic conditions.

Aqueous 2, 4, 6-trimethylpyridine $\left(40 \mathrm{mg} \cdot \mathrm{kg}^{-1}\right)$ was used as internal standard for quantitative analysis. The quantitative calculation $\left(\mathrm{mg} \cdot \mathrm{kg}^{-1}\right)$ was based on

$$
\text { concentration }(\text { each compound }))=\frac{\text { concentration } \quad(\text { internal standard }) \times \text { peak area }(\text { each compound })}{\text { peak area }(\text { internal standard })} .
$$

OAV for each volatile compound was calculated using the equation $\mathrm{OAV}=c / t$, where $c$ is the total concentration of the compound in the yogurt and $t$ is the odor threshold value. Compounds with OAV $>1$ were considered as odoractive compounds [27].
2.5. Statistical Analyses. All volatile concentration data represent the average of the triplicate measurements. Analysis of variance (ANOVA) followed by Turkey and Dunnett's multiple comparison test was adopted to evaluate the differences in volatile concentrations among yogurt 
samples. Heat map was performed using MultiExp to assess differences in volatile compounds and odor-active compounds, respectively. Unless specified, $p$ values of $<0.05$ were considered statistically significant.

\section{Results and Discussion}

3.1. Volatile Composition of Yogurts by S. thermophilus at Different Fermentation Times. The concentrations of identified volatiles in the yogurts are provided in Table 1. A total of 53 volatile compounds including 11 aldehydes, 10 ketones, 8 acids, 7 benzene derivatives, 13 hydrocarbons, and 4 other compounds were detected. It can be seen from Table 1 that fermentation time had a significant impact on the volatile profiles of yogurts. A total of $35,38,41,40$, and 36 volatile compounds, for which the total concentrations ranged from 1042.44 to $2810.78 \mathrm{mg} \cdot \mathrm{kg}^{-1}$, were detected in the fermented samples collected at $0,1.5,3,4.5$, and $6.0 \mathrm{~h}$, respectively. Twenty-three constituents were simultaneously present in all of the samples. Ketones (42.20\%) and hydrocarbons $(54.45 \%)$ were the predominant volatile components in $0 \mathrm{~h}$ sample, whereas acids (64.41\%) were the main constituents in $6.0 \mathrm{~h}$ sample. In addition, ketones (11.28\%) and hydrocarbons (19.11\%) also showed relative low content in $6.0 \mathrm{~h}$ sample.

A total of 11 aldehyde compounds were detected, being $8,9,9,8$, and 7 for the yogurts collected at $0,1.5,3,4.5$, and $6.0 \mathrm{~h}$, respectively. Of these aldehyde compounds, three of them contained benzene, while the other eight aldehydes belonged to $n$-alkanals. The concentration of aldehydes was relatively low, and the total concentrations of aldehydes, ranging from 36.64 to $17.99 \mathrm{mg} \cdot \mathrm{kg}^{-1}$, were significantly different $(p<0.05)$ in samples fermented at different times. Of the 11 detected aldehydes, benzaldehyde, octanal, nonanal, 2,4-dimethyl-benzaldehyde, (E,E)-2,4-decadienal, and tetradecanal were detected in all samples during the whole fermentation process and presented obvious dynamic changes. Only benzeneacetaldehyde and (E)-2-decenal were detected in the intermediate stage $(3.0 \mathrm{~h})$. Only undecanal, and not decanal and dodecanal, was present in the end of fermentation $(6.0 \mathrm{~h})$. Aldehydes usually dynamically change in yogurt during fermentation. They can be derived from the catabolism of amino acids [28] or the decomposition of hydroperoxide, which is an oxidation product of unsaturated fatty acids [2]. At the same time, aldehydes can be reduced to alcohols by alcohol dehydrogenases or oxidized to carboxylic acids by an aldehyde dehydrogenase [29]. Therefore, changes in the content of aldehydes have an important influence on the composition of volatile components during the fermentation of yogurt by $S$. thermophiles.

Ten ketones were detected in all samples, of which seven belonged to methyl ketones. The total concentrations of ketones were between $267.55(3.0 \mathrm{~h})$ and $562.43 \mathrm{mg} \cdot \mathrm{kg}^{-1}$ ( $4.5 \mathrm{~h})$. Six similar ketone compounds, including 2-heptanone, 2-nonanone, 2-undecanone, 2-tridecanone, 2-pentadecanone, and 6-heptyltetrahydro- $2 \mathrm{H}$-pyran-2-one, were detected in all samples. 2-Nonen-4-one and (Z)-dihydro-5(2-octenyl)-2(3H)-furanone were lacking in $0-3.0 \mathrm{~h}$ and
$0-1.5 \mathrm{~h}$ fermented yogurt samples, and 2-decanone and 2dodecanone were lacking in $4.5 \mathrm{~h}$ and $6.0 \mathrm{~h}$ fermented yogurt samples. Ketones were the dominant volatile components in the initial stage of fermentation, and 2-heptanone, 2-nonanone, 2-undecanone 2-tridecanone, and ( $\mathrm{Z}$-dihydro-5-(2octenyl)-2(3H)-furanone exceeded $5 \%$ in $0,1.5$, and $3.0 \mathrm{~h}$ yogurt samples. There was little change in content of 2undecanone and 2-tridecanone during the initial stage $(0-1.5 \mathrm{~h})$; their content peaked in the intermediate stage $(3.0 \mathrm{~h})$ and dropped sharply at $4.5 \mathrm{~h}$.

All of the values were expressed as mean $(n=3) \pm$ standard deviation; RI : retention index; SD : standard deviation; nd: not detected; mean values in the same row with different letters indicate the significant differences between clusters $(p<0.05)$ were maintained at relatively low levels in the late stage (4.5-6.0 h). Ketones are common volatile compounds in dairy products, and raw milk is an important source of ketones. Fermentation by $S$. thermophiles has an important effect on the content of ketones. At first, the preheating treatment accelerates the formation of ketone compounds in the milk [20]. Then ketone compounds can be generated from autoxidation reactions of unsaturated fatty acids during fermentation [20]. For example, 2-heptanone is formed by $\beta$-oxidation of saturated fatty acids followed by decarboxylation or by decarboxylation of $\beta$-ketoacids naturally present in milk fat [30].

Eight acids were detected in all yogurt samples. Acids were the group of compounds most affected by S. thermophilus fermentation. The content of acids significantly increased $(p<0.05)$ during the whole fermentation process. In the initial stage $(0 \mathrm{~h})$ of yogurt fermentation, only dodecanoic acid and tetradecanoic acid with a total content $11.90 \mathrm{mg} \cdot \mathrm{kg}^{-1}$ were detected. At the end of fermentation $(6.0 \mathrm{~h})$, eight acids with $1866.56 \mathrm{mg} \cdot \mathrm{kg}^{-1}$ total content were detected, and acids became the predominant volatile components in sample. A large number of new acid compounds were present in yogurt at different fermentation times. For example, octanoic acid, decanoic acid, hexanoic acid, undecanoic acid, nonanoic acid, and tridecanoic acid were first detected in $1.5,3.0,4.5$, and $6.0 \mathrm{~h}$ yogurt samples, and the content of these compounds increased along with the increasing of fermentation time. All of the acids belonged to straight chain carboxylic acids in fermented yogurt sample. Lipolysis is thought to be the main pathway for the formation of carboxylic acids, followed by lactose metabolism [31]. Carboxylic acids not only are aroma components but also can serve as precursors for the formation of methyl ketones, alcohols, lactones, aldehydes, and esters [31]. Among the various detected compounds, the change in acid compounds was the largest not only in composition of the component but also in the content of the component. These acids may have an important impact on the final odor quality of the yogurt.

Seven benzene derivatives were detected in yogurts during fermentation by $S$. thermophiles. These compounds were also less abundant in samples. The total concentrations of benzene derivatives were about $30 \mathrm{mg} \cdot \mathrm{kg}^{-1}$ and were significantly different $(p<0.05)$ in samples which were 
TABLE 1: Content of volatile compounds in yogurt by S. thermophilus at different fermentation times.

\begin{tabular}{|c|c|c|c|c|c|c|}
\hline \multirow{2}{*}{ RI } & \multirow{2}{*}{ Compound names } & \multicolumn{5}{|c|}{ Content $(\mathrm{mg} \cdot \mathrm{kg}-1)$} \\
\hline & & $0 \mathrm{~h}$ & $1.5 \mathrm{~h}$ & $3.0 \mathrm{~h}$ & $4.5 \mathrm{~h}$ & $6.0 \mathrm{~h}$ \\
\hline & & & Aldehydes & & & \\
\hline 955 & Benzaldehyde & $1.34 \pm 0.18^{\mathrm{d}}$ & $1.86 \pm 0.31^{\mathrm{c}}$ & $2.03 \pm 0.17^{\mathrm{c}}$ & $3.23 \pm 0.08^{\mathrm{b}}$ & $3.68 \pm 0.26^{\mathrm{a}}$ \\
\hline 1004 & Octanal & $1.45 \pm 0.13^{\mathrm{a}}$ & $1.65 \pm 0.39^{\mathrm{a}}$ & $1.49 \pm 0.08^{\mathrm{a}}$ & $0.76 \pm 0.26^{\mathrm{b}}$ & $1.28 \pm 0.24^{\mathrm{a}}$ \\
\hline 1045 & Benzeneacetaldehyde & nd & nd & $1.26 \pm 0.28^{\mathrm{a}}$ & nd & nd \\
\hline 1106 & Nonanal & $8.54 \pm 2.01^{\mathrm{a}}$ & $4.28 \pm 0.61^{\mathrm{b}}$ & $3.34 \pm 0.31 b^{c}$ & $1.68 \pm 0.24^{\mathrm{c}}$ & $3.48 \pm 0.12^{\mathrm{bc}}$ \\
\hline 1206 & Decanal & $2.35 \pm 0.07^{\mathrm{a}}$ & $1.20 \pm 0.20^{\mathrm{b}}$ & $1.14 \pm 0.13^{\mathrm{b}}$ & $1.28 \pm 0.18^{\mathrm{b}}$ & nd \\
\hline 1216 & 2,4-Dimethyl-benzaldehyde & $6.62 \pm 0.34^{\mathrm{b}}$ & $3.41 \pm 0.31^{\mathrm{c}}$ & $3.56 \pm 0.21^{\mathrm{c}}$ & $3.54 \pm 0.54^{\mathrm{c}}$ & $16.49 \pm 2.14^{\mathrm{a}}$ \\
\hline 1263 & (E)-2-Decenal & nd & $0.64 \pm 0.06^{\mathrm{a}}$ & nd & nd & nd \\
\hline 1308 & Undecanal & nd & nd & nd & nd & $2.56 \pm 0.20^{\mathrm{a}}$ \\
\hline 1318 & (E,E)-2,4-Decadienal & $2.22 \pm 0.28^{\mathrm{a}}$ & $1.46 \pm 0.16^{\mathrm{b}}$ & $1.71 \pm 0.12^{\mathrm{b}}$ & $1.78 \pm 0.06^{\mathrm{b}}$ & $2.23 \pm 0.14^{\mathrm{a}}$ \\
\hline 1410 & Dodecanal & $8.75 \pm 1.14^{\mathrm{a}}$ & $5.30 \pm 0.55^{\mathrm{b}}$ & $6.29 \pm 0.79^{b}$ & $0.92 \pm 0.05^{\mathrm{c}}$ & nd \\
\hline \multirow[t]{2}{*}{1614} & Tetradecanal & $5.38 \pm 0.98^{\mathrm{bc}}$ & $4.74 \pm 0.37^{\mathrm{c}}$ & $6.34 \pm 0.66^{\mathrm{ab}}$ & $4.80 \pm 0.39^{c}$ & $6.83 \pm 0.98^{\mathrm{a}}$ \\
\hline & Subtotal & $36.64 \pm 4.25^{\mathrm{a}}$ & $\begin{array}{l}24.54 \pm 2.15^{\mathrm{b}} \\
\text { Ketones }\end{array}$ & $27.15 \pm 2.11^{\mathrm{b}}$ & $17.99 \pm 0.45^{\mathrm{c}}$ & $36.54 \pm 2.66^{\mathrm{a}}$ \\
\hline 891 & 2-Heptanone & $54.12 \pm 2.90^{\mathrm{c}}$ & $56.57 \pm 7.84^{\mathrm{c}}$ & $65.25 \pm 6.59^{\mathrm{ab}}$ & $61.17 \pm 4.63^{\mathrm{ab}}$ & $71.84 \pm 7.59^{\mathrm{a}}$ \\
\hline 1094 & 2-Nonanone & $64.67 \pm 4.98^{\mathrm{b}}$ & $65.34 \pm 6.84^{\mathrm{b}}$ & $79.52 \pm 3.98^{\mathrm{a}}$ & $60.84 \pm 4.12^{\mathrm{b}}$ & $66.71 \pm 6.37^{b}$ \\
\hline 1130 & 2-Nonen-4-one & nd & nd & nd & $3.05 \pm 0.57^{\mathrm{a}}$ & $2.58 \pm 0.23^{\mathrm{a}}$ \\
\hline 1199 & 2-Decanone & $4.52 \pm 0.40^{\mathrm{a}}$ & $3.38 \pm 0.29^{\mathrm{b}}$ & $3.54 \pm 0.35^{\mathrm{b}}$ & nd & nd \\
\hline 1296 & 2-Undecanone & $88.21 \pm 10.22^{\mathrm{b}}$ & $84.38 \pm 7.37^{\mathrm{b}}$ & $114.18 \pm 12.05^{\mathrm{a}}$ & $38.61 \pm 1.16^{\mathrm{c}}$ & $45.79 \pm 4.94^{\mathrm{c}}$ \\
\hline 1399 & 2-Dodecanone & $1.98 \pm 0.36^{\mathrm{b}}$ & $2.26 \pm 0.37^{\mathrm{b}}$ & $2.78 \pm 0.36^{\mathrm{a}}$ & nd & nd \\
\hline 1498 & 2-Tridecanone & $112.01 \pm 14.09^{\mathrm{b}}$ & $108.92 \pm 8.41^{\mathrm{b}}$ & $135.40 \pm 14.91^{\mathrm{a}}$ & $35.88 \pm 2.23^{\mathrm{c}}$ & $45.10 \pm 2.02^{\mathrm{c}}$ \\
\hline 1658 & $\begin{array}{l}\text { (Z)-Dihydro-5-(2-octeny)-2(3H)- } \\
\text { furanone }\end{array}$ & nd & nd & $7.64 \pm 0.49^{\mathrm{b}}$ & $6.13 \pm 0.68^{\mathrm{c}}$ & $10.33 \pm 0.23 a$ \\
\hline 1699 & 2-Pentadecanone & $79.83 \pm 8.94^{\mathrm{b}}$ & $90.08 \pm 9.04^{\mathrm{b}}$ & $118.29 \pm 10.71^{\mathrm{a}}$ & $24.67 \pm 2.19^{c}$ & $17.51 \pm 2.69^{c}$ \\
\hline \multirow{2}{*}{1710} & 6-Heptyltetrahydro-2H-pyran-2-one & $34.58 \pm 1.90^{\mathrm{b}}$ & $34.26 \pm 2.43^{\mathrm{b}}$ & $35.83 \pm 3.35^{\mathrm{b}}$ & $37.20 \pm 1.25^{\mathrm{b}}$ & $57.08 \pm 0.92^{\mathrm{a}}$ \\
\hline & Subtotal & $439.92 \pm 33.78^{\mathrm{b}}$ & $\begin{array}{l}445.19 \pm 41.72^{\mathrm{b}} \\
\text { Acids }\end{array}$ & $562.43 \pm 35.72^{\mathrm{a}}$ & $267.55 \pm 12.98^{\mathrm{c}}$ & $316.94 \pm 24.50^{c}$ \\
\hline 1008 & Hexanoic acid & nd & nd & nd & $5.17 \pm 0.25^{\mathrm{b}}$ & $30.26 \pm 3.54^{\mathrm{a}}$ \\
\hline 1194 & Octanoic acid & nd & $0.64 \pm 0.07^{\mathrm{c}}$ & $0.81 \pm 0.07^{\mathrm{c}}$ & $55.85 \pm 5.61^{\mathrm{b}}$ & $149.38 \pm 11.51^{\mathrm{a}}$ \\
\hline 1285 & Nonanoic acid & nd & nd & nd & nd & $18.36 \pm 1.83^{\mathrm{a}}$ \\
\hline 1377 & Decanoic acid & nd & nd & $2.68 \pm 0.28^{\mathrm{b}}$ & $70.75 \pm 4.47^{\mathrm{b}}$ & $782.24 \pm 78.33^{\mathrm{a}}$ \\
\hline 1473 & Undecanoic acid & nd & nd & nd & $9.88 \pm .49^{\mathrm{b}}$ & $15.80 \pm 0.40^{\mathrm{a}}$ \\
\hline 1568 & Dodecanoic acid & $10.92 \pm 2.43^{c}$ & $2.21 \pm 0.17^{\mathrm{c}}$ & $6.18 \pm 0.79^{c}$ & $66.71 \pm 7.11^{b}$ & $564.28 \pm 58.05^{\mathrm{a}}$ \\
\hline 1666 & Tridecanoic acid & nd & nd & nd & nd & $5.97 \pm 0.78^{\mathrm{a}}$ \\
\hline \multirow[t]{3}{*}{1765} & Tetradecanoic acid & $0.98 \pm 0.00^{\mathrm{c}}$ & $5.26 \pm 0.42^{\mathrm{c}}$ & $20.96 \pm 3.87 b^{c}$ & $41.66 \pm 3.07^{\mathrm{b}}$ & $300.27 \pm 32.23^{\mathrm{a}}$ \\
\hline & Subtotal & $11.90 \pm 2.43^{\mathrm{c}}$ & $8.11 \pm 0.29^{c}$ & $30.64 \pm 4.96^{\mathrm{c}}$ & $250.03 \pm 20.26^{\mathrm{b}}$ & $1866.56 \pm 174.63^{\circ}$ \\
\hline & & & nzene derivatives & & & \\
\hline 852 & Ethylbenzene & $3.98 \pm 0.41^{\mathrm{b}}$ & $5.25 \pm 0.52^{\mathrm{a}}$ & $5.44 \pm 0.28^{\mathrm{a}}$ & $5.28 \pm 0.97^{\mathrm{a}}$ & $5.54 \pm 0.21^{\mathrm{a}}$ \\
\hline 860 & p-Xylene & $13.19 \pm 1.68^{\mathrm{a}}$ & $15.12 \pm 0.88^{\mathrm{a}}$ & $13.52 \pm 0.49^{\mathrm{a}}$ & $13.63 \pm 1.88^{\mathrm{a}}$ & $13.42 \pm 0.83^{\mathrm{a}}$ \\
\hline 884 & Styrene & $12.71 \pm 1.97^{\mathrm{a}}$ & $12.27 \pm 1.81^{\mathrm{a}}$ & $11.93 \pm 1.25^{\mathrm{a}}$ & $10.19 \pm 0.74^{\mathrm{a}}$ & $11.05 \pm 0.84^{\mathrm{a}}$ \\
\hline 1118 & $1,2,4,5$-Tetramethyl-benzene & $0.99 \pm 0.15^{\mathrm{b}}$ & $2.33 \pm 0.11^{\mathrm{a}}$ & $1.98 \pm 0.34^{\mathrm{a}}$ & $1.26 \pm 0.06^{\mathrm{b}}$ & $1.22 \pm 0.18^{\mathrm{b}}$ \\
\hline 1183 & Naphthalene & $1.14 \pm 0.07^{\mathrm{a}}$ & $0.86 \pm 0.08^{\mathrm{a}}$ & $0.71 \pm 0.10^{\mathrm{c}}$ & $1.00 \pm 0.08^{\mathrm{ab}}$ & $1.14 \pm 0.05^{\mathrm{a}}$ \\
\hline 1289 & 1-Methyl-naphthalene & $3.49 \pm 0.15^{\mathrm{a}}$ & $2.00 \pm 0.18^{\mathrm{b}}$ & $2.09 \pm 0.16^{\mathrm{b}}$ & $2.26 \pm 0.18^{b}$ & nd \\
\hline \multirow[t]{3}{*}{1417} & 2,3-Dimethyl-naphthalene & $1.05 \pm 0.04^{\mathrm{a}}$ & $0.65 \pm 0.09^{\mathrm{b}}$ & $0.44 \pm 0.03^{c}$ & $0.43 \pm 0.08^{c}$ & nd \\
\hline & Subtotal & $36.56 \pm 3.83^{\mathrm{ab}}$ & $38.48 \pm 2.97^{\mathrm{a}}$ & $36.12 \pm 2.04^{\mathrm{ab}}$ & $34.05 \pm 2.37^{\mathrm{ab}}$ & $32.36 \pm 1.95^{\mathrm{b}}$ \\
\hline & & & Hydrocarbons & & & \\
\hline 900 & Nonane & $539.67 \pm 72.04^{\mathrm{a}}$ & $564.57 \pm 46.61^{\mathrm{a}}$ & $538.43 \pm 58.91^{\mathrm{a}}$ & $550.29 \pm 46.52^{\mathrm{a}}$ & $522.47 \pm 27.75^{\mathrm{a}}$ \\
\hline 1000 & Decane & $1.11 \pm 0.15^{\mathrm{a}}$ & $0.58 \pm 0.07^{\mathrm{b}}$ & $0.60 \pm 0.04^{\mathrm{b}}$ & nd & nd \\
\hline 1100 & Undecane & nd & nd & $0.74 \pm 0.10^{\mathrm{b}}$ & $1.35 \pm 0.09^{\mathrm{a}}$ & $1.34 \pm 0.15^{\mathrm{a}}$ \\
\hline 1197 & 1-Dodecene & nd & $3.39 \pm 0.30^{\mathrm{b}}$ & $4.35 \pm 0.61^{\mathrm{a}}$ & $0.67 \pm 0.13^{c}$ & nd \\
\hline 1200 & Dodecane & $1.35 \pm 0.10^{\mathrm{a}}$ & $0.66 \pm 0.10^{\mathrm{b}}$ & $0.76 \pm 0.07^{\mathrm{b}}$ & $0.66 \pm 0.03^{\mathrm{b}}$ & nd \\
\hline 1300 & Tridecane & nd & $0.61 \pm 0.08^{\mathrm{c}}$ & $0.72 \pm 0.09^{c}$ & $1.21 \pm 0.15^{\mathrm{b}}$ & $1.61 \pm 0.16^{\mathrm{a}}$ \\
\hline 1224 & 4,8-Dimethyl-undecane & $1.09 \pm 0.16^{\mathrm{a}}$ & nd & nd & nd & nd \\
\hline 1396 & 1-Tetradecene & nd & $1.04 \pm 0.10^{\mathrm{b}}$ & $1.09 \pm 0.28^{\mathrm{b}}$ & $2.04 \pm 0.10^{\mathrm{a}}$ & nd \\
\hline 1400 & Tetradecane & $3.45 \pm 0.26^{\mathrm{a}}$ & $1.74 \pm 0.20^{\mathrm{b}}$ & $1.49 \pm 0.15^{\mathrm{b}}$ & $1.38 \pm 0.26^{\mathrm{b}}$ & nd \\
\hline 1494 & 1-Pentadecene & nd & nd & nd & nd & $6.41 \pm 0.48^{\mathrm{a}}$ \\
\hline 1500 & Pentadecane & $8.24 \pm 0.61^{\mathrm{a}}$ & nd & nd & nd & nd \\
\hline 1600 & Hexadecane & $12.68 \pm 0.87^{\mathrm{a}}$ & $7.04 \pm 0.64^{\mathrm{b}}$ & $6.08 \pm 0.48^{\mathrm{b}}$ & $2.01 \pm 0.44^{\mathrm{d}}$ & $4.60 \pm 0.52^{c}$ \\
\hline 1692 & 1-Heptadecene & nd & nd & nd & $7.56 \pm 0.51^{\mathrm{a}}$ & $0.70 \pm 0.06^{\mathrm{b}}$ \\
\hline
\end{tabular}


TABle 1: Continued.

\begin{tabular}{|c|c|c|c|c|c|c|}
\hline \multirow{2}{*}{ RI } & \multirow{2}{*}{ Compound names } & \multicolumn{5}{|c|}{ Content (mg.kg-1) } \\
\hline & & $0 \mathrm{~h}$ & $1.5 \mathrm{~h}$ & $3.0 \mathrm{~h}$ & $4.5 \mathrm{~h}$ & $6.0 \mathrm{~h}$ \\
\hline & Subtotal & $567.59 \pm 72.94^{\mathrm{a}}$ & $\begin{array}{r}579.64 \pm 45.95^{\mathrm{a}} \\
\text { Other }\end{array}$ & $554.28 \pm 60.27^{\mathrm{a}}$ & $567.17 \pm 46.77^{\mathrm{a}}$ & $537.12 \pm 28.02^{\mathrm{a}}$ \\
\hline 917 & Diethyl disulfide & nd & $2.93 \pm 0.27^{\mathrm{a}}$ & $3.11 \pm 0.20^{\mathrm{a}}$ & nd & nd \\
\hline 991 & 2-Pentyl-furan & $2.19 \pm 0.38^{\mathrm{a}}$ & nd & nd & nd & nd \\
\hline 1029 & Limonene & $3.67 \pm 0.69^{\mathrm{a}}$ & $3.32 \pm 0.43^{\mathrm{a}}$ & $3.23 \pm 0.21^{\mathrm{a}}$ & $1.23 \pm 0.26^{\mathrm{b}}$ & $1.26 \pm 0.12^{\mathrm{b}}$ \\
\hline \multirow[t]{3}{*}{1515} & 2,4-Bis(1,1-dimethylethyl)-phenol & $46.85 \pm 5.33^{\mathrm{a}}$ & $23.11 \pm 2.82^{\mathrm{b}}$ & $22.55 \pm 1.99^{\mathrm{b}}$ & $19.20 \pm 1.22^{\mathrm{b}}$ & $19.99 \pm 1.89^{\mathrm{b}}$ \\
\hline & Subtotal & $52.71 \pm 6.06^{\mathrm{a}}$ & $29.36 \pm 3.49^{\mathrm{b}}$ & $28.89 \pm 2.39^{\mathrm{b}}$ & $20.43 \pm 1.47^{\mathrm{c}}$ & $21.26 \pm 1.91^{\mathrm{c}}$ \\
\hline & Total & $1145.32 \pm 116.21^{\mathrm{b}}$ & $1125.33 \pm 56.95^{\mathrm{b}}$ & $1239.52 \pm 102.70^{\mathrm{b}}$ & $1157.22 \pm 46.55^{\mathrm{b}}$ & $2810.78 \pm 142.56^{\mathrm{a}}$ \\
\hline
\end{tabular}

fermented under different fermentation time. With the exception of 1-methyl-naphthalene and 2,3-dimethylnaphthalene, which were not detected in the final stage fermentation sample, other benzene derivatives including ethylbenzene, p-xylene, styrene, 1,2,4,5-tetramethyl-benzene, and naphthalene were present in all samples. Throughout the fermentation process, benzene derivatives showed relatively high stability. They are usually from milk of cows fed on pasture grass [32] and maintained a relatively stable content during the entire fermentation process.

Hydrocarbons were the richest group in compounds identified in all of the samples, and 13 hydrocarbons were detected in yogurts during fermentation by $S$. thermophiles. Seven, eight, nine, nine, and six hydrocarbons were detected from 0 to $6.0 \mathrm{~h}$ fermentation samples, respectively. The total content of hydrocarbons did not significantly change $(p>0.05)$ during the fermentation process. Nonane, which was the dominant hydrocarbon of about $550 \mathrm{mg} \cdot \mathrm{kg}^{-1}$, kept a relatively stable content during the whole fermentation process. The amounts of other hydrocarbons were generally low and fluctuated during fermentation. 4,8-Dimethylundecane and pentadecane were only present in the initial stage $(0 \mathrm{~h})$. Decane and tetradecane were present in the early stage $(0-4.5 \mathrm{~h}), 1$-dodecene and 1-tetradecene were present in the middle stage $(1.5-4.5 \mathrm{~h})$, undecane, tridecane, 1pentadecene, and 1-heptadecene were mainly present in yogurts fermented after $1.5 \mathrm{~h}$, and nonane and hexadecane were the most frequently detected hydrocarbons during the entire stage $(0-6.0 \mathrm{~h})$. Hydrocarbons are generally derived from lipid oxidation [31]. Despite the frequent detection of hydrocarbons in all samples, they do not contribute to yogurt aroma due to their low detection amounts and high perception threshold [33].

In addition, there were four other compounds detected in the yogurts during the fermentation process including diethyl disulfide, 2-pentyl-furan, limonene, and 2,4-bis(1,1dimethylethyl)-phenol. Most of them were common volatile compounds in yogurt. Diethyl disulfide, which is usually produced by microbial metabolism of sulfur-containing amino acids or decomposition of sulfydryl groups during heat treatment before yogurt fermentation [34], was detected in the middle fermentation stage. 2-Pentyl-furan, a secondary oxidation product of linoleic acids, was only present in the $0 \mathrm{~h}$ sample [35]. Limonene may be from forage, which is transferred to milk from a cow's feed [32]. There was no significant change in the early stage, and the decrease in the later period was obvious. 2,4-Bis(1,1-dimethylethyl)-phenol significantly decreased in the earlier fermentation period.

3.2. OAVs of Volatile Compounds in Yogurts by S. thermophilus at Different Times. Although dozens of volatile compounds were detected in yogurt after $S$. thermophilus fermentation at different time points, not all of the components had a large impact on the overall aroma characteristic of the samples. To evaluate the contribution of various volatile compounds on olfactory impression, characteristic aroma compounds were determined by OAVs, which were calculated on the basis of the ratio of the concentration of the compound to odor threshold. The aroma characteristics of 30 volatile compounds were described in previous works $[2,24,25]$. As shown in Table 2, OAVs were $>1$ in 29 volatile compounds. These compounds played a critical role in yogurt by $S$. thermophilus fermentation at different time points. A total of 19, 19, 20, 22, and 20 odor-active compounds were detected in yogurt at $0,1.5,3.0$, 4.5 , and $6.0 \mathrm{~h}$ fermentation, respectively.

As shown in Table 2, aldehydes made up the largest group of odor-active volatiles, of which nine aldehydes were detected as odor-active compounds in the samples. Due to lower thresholds, even lower levels of aldehydes were detected, which had important effects on the odor quality of the yogurt samples. Nonanal, (E,E)-2,4-decadienal, and dodecanal showed extremely high OAVs (>1000) and were responsible for the green, woody odor, so they made great contributions to the flavor of yogurt during fermentation by S. thermophiles. It is worth noting that the OAV of (E,E)-2,4decadienal was between 14,623 and 22,278 and was the most important odor-active compound in the yogurt samples. Due to the extremely low odor threshold of (E,E)-2,4-decadienal $\left(0.0001 \mathrm{mg} \cdot \mathrm{kg}^{-1}\right.$, fatty and green), trace changes had a huge impact on odor intensity. Benzeneacetaldehyde (sweet, flora), decanal (fatty), and undecanal (fatty) had high OAVs (100-1000) and were only detected in 3.0, 1.5, and $6.0 \mathrm{~h}$ yogurt samples, respectively. Nonanal, with a "sweet, floral, citrus, and grass" odor, had high OAVs (100-1000) in the initial phase and medium OAVs (10-100) in the last phase. Except for the late stage, decanal had medium OAVs in the yogurt samples. Benzaldehyde, which contributed almond and burnt sugar, had low OAVs (1-10) throughout the fermentation process. Among the detected odor-active aldehydes, nonanal and decanal were also detected in yogurt fermented by L. plantarum, but they did not contribute odor 
TABLE 2: OAVs of volatile compounds in yogurt fermented by S. thermophilus at different times.

\begin{tabular}{|c|c|c|c|c|c|c|c|}
\hline \multirow{2}{*}{ Compound names } & \multirow{2}{*}{ Odor descriptor } & \multirow{2}{*}{ Odor threshold $\left(\mathrm{mg} \cdot \mathrm{kg}^{-1}\right)$} & \multicolumn{5}{|c|}{ OAV } \\
\hline & & & $0 \mathrm{~h}$ & $1.5 \mathrm{~h}$ & $3.0 \mathrm{~h}$ & $4.5 \mathrm{~h}$ & $6.0 \mathrm{~h}$ \\
\hline \multicolumn{8}{|l|}{ Aldehydes } \\
\hline Benzaldehyde & Almond, burnt sugar ${ }^{3}$ & 0.35 & 3.8 & 5.3 & 5.8 & 9.2 & 10.5 \\
\hline Octanal & Fat, lemon, green ${ }^{3}$ & 0.0009 & 1608.2 & 1831.1 & 1661.1 & 842.6 & 1423.4 \\
\hline Benzeneacetaldehyde & Sweet, flora ${ }^{24}$ & 0.004 & 0.0 & 0.0 & 315.3 & 0.0 & 0.0 \\
\hline Nonanal & Sweet, floral, citrus, grass ${ }^{3}$ & 0.04 & 213.4 & 106.9 & 83.4 & 41.9 & 86.9 \\
\hline Decanal & Fatty ${ }^{3}$ & 0.03 & 78.3 & 39.9 & 38.0 & 42.5 & 0.0 \\
\hline (E)-2-Decenal & Fatty, waxy, green ${ }^{24}$ & 0.001 & 0.0 & 640.7 & 0.0 & 0.0 & 0.0 \\
\hline Undecanal & Fatty $^{3}$ & 0.01 & 0.0 & 0.0 & 0.0 & 0.0 & 255.7 \\
\hline (E,E)-2,4-Decadienal & Fatty, green ${ }^{24}$ & 0.0001 & 22156.6 & 14623.5 & 17060.5 & 17810.2 & 22278.7 \\
\hline Dodecanal & Soapy, waxy, citrus ${ }^{24}$ & 0.0015 & 5836.5 & 3535.7 & 4192.9 & 615.0 & 0.0 \\
\hline \multicolumn{8}{|l|}{ Ketones } \\
\hline 2-Heptanone & Fresh cream $^{25}$ & 0.14 & 386.6 & 404.1 & 466.1 & 437.0 & 513.1 \\
\hline 2-Nonanone & Grass, fruity, floral ${ }^{25}$ & 0.08 & 808.4 & 816.7 & 994.0 & 760.5 & 833.9 \\
\hline 2-Nonen-4-one & Fruity, floral ${ }^{3}$ & 0.0009 & 0.0 & 0.0 & 0.0 & 3391.7 & 2870.4 \\
\hline 2-Decanone & Sweet, waxy ${ }^{3}$ & 0.08 & 56.5 & 42.3 & 44.2 & 0.0 & 0.0 \\
\hline 2-Undecanone & Orange, grass, fresh ${ }^{25}$ & 0.08 & 1102.6 & 1054.7 & 1427.2 & 482.7 & 572.3 \\
\hline 2-Dodecanone & Orange, grass, fresh ${ }^{24}$ & 0.08 & 24.8 & 28.3 & 34.8 & 0.0 & 0.0 \\
\hline \multicolumn{8}{|l|}{ Acids } \\
\hline Hexanoic acid & Spicy, rancidity ${ }^{25}$ & 1.84 & 0.0 & 0.0 & 0.0 & 2.8 & 16.4 \\
\hline Octanoic acid & Chess, sweaty ${ }^{25}$ & 1.9 & 0.0 & 0.3 & 0.4 & 29.4 & 78.6 \\
\hline Decanoic acid & Rancid $^{3}$ & 3 & 0.0 & 0.0 & 0.9 & 23.6 & 260.7 \\
\hline Undecanoic acid & Rancid $^{24}$ & 10 & 0.0 & 0.0 & 0.0 & 1.0 & 1.6 \\
\hline Dodecanoic acid & Rancid $^{24}$ & 10 & 1.1 & 0.2 & 0.6 & 6.7 & 56.4 \\
\hline Tridecanoic acid & Rancid $^{24}$ & 10 & 0.0 & 0.0 & 0.0 & 0.0 & 0.6 \\
\hline Tetradecanoic acid & Rancid $^{24}$ & 10 & 0.1 & 0.5 & 2.1 & 4.2 & 30.0 \\
\hline \multicolumn{8}{|l|}{ Benzene derivatives } \\
\hline Ethylbenzene & Gasoline $^{24}$ & 0.2 & 19.9 & 26.2 & 27.2 & 26.4 & 27.7 \\
\hline p-Xylene & Phenolic $^{24}$ & 1 & 13.2 & 15.1 & 13.5 & 13.6 & 13.4 \\
\hline Styrene & Sweet, balsamic ${ }^{24}$ & 0.05 & 254.2 & 245.5 & 238.7 & 203.9 & 220.9 \\
\hline Naphthalene & Phenolic ${ }^{24}$ & 0.006 & 190.6 & 144.0 & 119.1 & 166.0 & 190.0 \\
\hline 1-Methyl-naphthalene & Phenolic $^{24}$ & 0.0075 & 465.1 & 266.7 & 278.4 & 301.4 & 0.0 \\
\hline \multicolumn{8}{|l|}{ Other compounds } \\
\hline Diethyl disulfide & Cabbage, sulfide, gasoline $e^{25}$ & 0.01 & 0.0 & 293.0 & 310.7 & 0.0 & 0.0 \\
\hline 2-Pentyl-furan & Green, $\mathrm{fat}^{3}$ & 0.006 & 364.9 & 0.0 & 0.0 & 0.0 & 0.0 \\
\hline Limonene & Orange, mint $^{25}$ & 0.2 & 18.4 & 16.6 & 16.2 & 6.2 & 6.3 \\
\hline
\end{tabular}

Odor description and threshold were provided in references $[3,24,25]$.

to sample due to OAV $<1$ [24]. Nonanal, (E)-decenal, and (E,E)-2,4-decadienal reportedly contribute "fatty," "fruity," and "fruity," odors, respectively, to fermented camel milk [36]. In addition, octanal and decanal contribute "fatty, lemon, green" and "green" odors to dairy products such as cheese [37].

Six ketones were found to affect the aroma characteristic of yogurt by $S$. thermophiles at different time points. Among them, 2-none-4-one, which contributed a "fruity, floral" odor, showed extremely high OAVs (>1000) in $4.5 \mathrm{~h}$ (3391) and $6.0 \mathrm{~h} \mathrm{(2870)}$ samples due to the low threshold $\left(0.0009 \mathrm{mg} \cdot \mathrm{kg}^{-1}\right)$. 2-Undecanone contributed an "orange, grass, fresh" odor with extremely high OAVs in 0-3.0 h samples (1102-1427) and high OAVs in 4.5-6.0 h yogurt samples (482-572). 2-Heptaone and 2-nonaone provided "fresh cream" and "grass, fruity, floral" odors with high OAVs during the whole fermentation process. 2-dodecanone contributed an "orange, grass, fresh" odor in the $0,1.5$, and $3.0 \mathrm{~h}$ samples with 24,28 , and $34 \mathrm{OAVs}$ that belonged to medium OAVs. Among the odor-active ketones, 2-heptone, 2-nonanone, and 2-undecanone contributed "fresh cream," "grass, fruity, floral," and "foam grass" odors to yogurt fermented by L. plantarum with medium OAVs [24]. 2Decanone, which contributes a "fresh cream" odor, was identified as an odor-active compound in fermented camel milk [36].

Among the acids with odor descriptions, most had OAVs $>1$ except for tridecanoic acid and mainly contributed odor in the later stage of fermentation. In the $4.5 \mathrm{~h}$ sample, hexanoic acid, undecanoic acid, dodecanoic acid, and tetradecanoic acid provided a "rancid" odor with low OAVs, and octanoic acid and decanoic acid also provided a "rancid" odor with medium OAVs. In the $6.0 \mathrm{~h}$ sample, the OAVs of hexanoic acid, octanoic acid, undecanoic acid, dodecanoic acid, and tetradecanoic acid increased to 10-100 and had medium odor intensity, whereas the OAV of decanoic acid increased to 260 and had high odor intensity. Hexanoic acid and octanoic acid with characteristic of "spicy, rancidity" and "chess, sweaty" odors were detected as odor-active compounds in yogurt fermented by L. plantarum with 


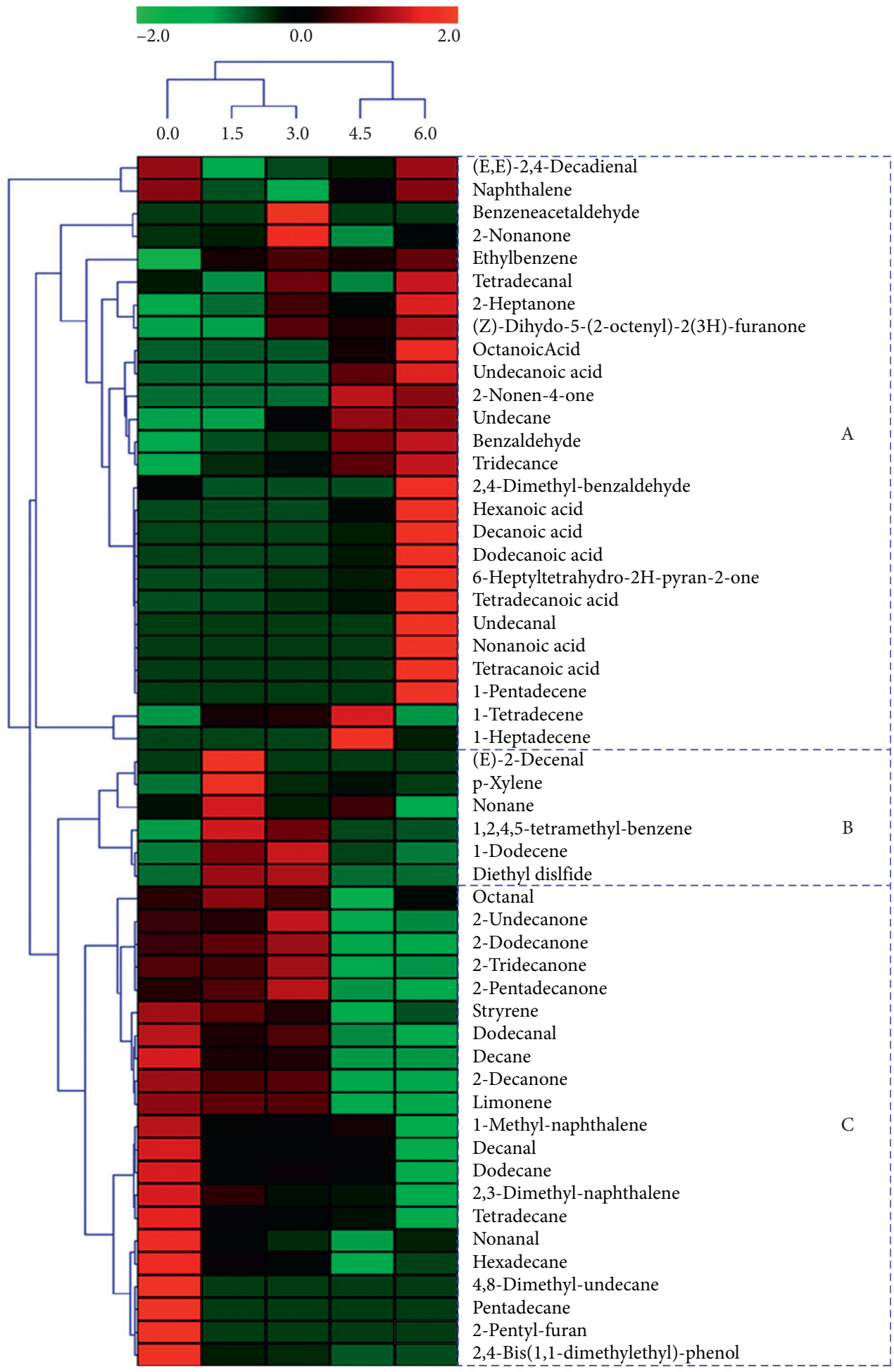

Figure 1: Heat map plots clusters of volatile compounds in yogurt fermented by S. thermophilus at different time points based on the content. Green colors indicate that volatile compound levels were less than the mean levels during yogurt fermentation, while red colors indicate that volatile compound levels were higher than the mean levels.

medium OAVs [24]. Undecanoic acid, decanoic acid, dodecanoic acid, and tetradecanoic acid provide odors such as "fatty," "sweet," "floral," and "waxy" in dairy products such as fermented camel milk [36] and cheese [37].

Five odor-active benzene derivatives including ethylbenzene, p-xylene, styrene, naphthalene, and 1-methyl-naphthalene give a "phenolic" odor to samples. Ethylbenzene and p-xylene had medium odor intensities, and styrene, naphthalene, and 1methyl-naphthalene had high odor intensities. Most of them retained a relatively stable odor intensity throughout the fermentation process. Benzene derivatives such as ethylbenzene and p-xylene reportedly provide "phenol, spice" and "leathery" 
aromas to yogurt. Other compounds were detected as active odor compounds in the samples. Diethyl disulfide and 2-pentylfuran had high OAVs at different fermentation times by $S$. thermophiles. Limonene had medium OAVs in yogurt samples fermented in $0-3.0 \mathrm{~h}$ and had low OAVs in yogurt samples fermented in $4.5-6.0 \mathrm{~h}$.

\subsection{Heat Map Analysis of Volatile Compounds in Yogurts} during Fermentation. A heat map was generated to show the variation in content of volatile compounds in yogurt during fermentation by $S$. thermophiles (Figure 1). Green colors indicate that the volatile compound levels were less than the mean level during yogurt fermentation, whereas the red colors indicate that volatile compound levels were higher than the mean levels. The samples collected from different stages were clustered into three clusters: the first cluster contained the $0 \mathrm{~h}$ sample, the second cluster contained the 1.5 and $3.0 \mathrm{~h}$ samples, and the third cluster contained the 4.5 and $6.0 \mathrm{~h}$ samples. According to the content of the volatile compounds, the samples were divided into three groups: A, B, and C. A group included six acids (octanoic acid, undecanoic acid, hexanoic acid, decanoic acid, dodecanoic acid, and tridecanoic acid), six aldehydes ((E,E)-2,4-decadienal, benzeneacetaldehyde, tetradecanal, benzaldehyde, 2,4-dimethylbenzaldehyde, and undecanal), five ketones (2-nonanone, 2heptanone, (Z)-dihydro-5-(2-octenyl)-2(3H)-furanone, 2nonen-4-one, and 6-heptyltetrahydro-2H- pyran-2-one), five hydrocarbons (undecane, tridecane, 1-pentadecene, 1-tetradecene, and 1-heptadecene), and two benzene derivatives (naphthalene and ethylbenzene). Most of the acids and unsaturated hydrocarbons were focused in this group. These compounds usually showed a high content in the later stage. The B group included six compounds, namely, (E)-2-decenal, p-xylene, nonane, 1,2,4,5-tetramethyl- benzene, 1-dodecene, and diethyl disulfide, which showed a high content in the medium stage. The $\mathrm{C}$ group, which had a high content in the original stage, included four aldehydes (octanal, dodecanal, decanal, and nonanal), four ketones (2-undecanone, 2dodecanone, 2-tridecanone, and 2-petadecanone), five hydrocarbons (decane, dodecane, tetradecane, hexadecane, and pentadecane), three benzene derivatives (styrene, 1-methylnaphthalene, and 2,3-dimethyl-naphthalene), and three other compounds (limonene, 2-pentyl-furan, and 2,4-dis(1,1dimethylethy)-phenol). Conclusions section should clearly explain the main findings and implications of the work, highlighting its importance and relevance.

Figure 2 shows the heat map of variation in the OAVs of volatile compounds in yogurt during fermentation. There were similar variations in OAVs with the content of volatile compounds from different fermentation times. Yogurt fermented for $0 \mathrm{~h}$ belonged to the first cluster, yogurts fermented for 1.5 and $3.0 \mathrm{~h}$ belonged to the second cluster, and yogurt fermented 4.5 and $6.0 \mathrm{~h}$ belonged to the third cluster. According to the OAVs that presented the odor intensity of the volatile compounds, the samples were divided into A, B, and C groups. Group A contained six compounds, which showed a high odor intensity in the $0 \mathrm{~h}$ yogurt sample including three aldehydes ((E,E)-2,4-

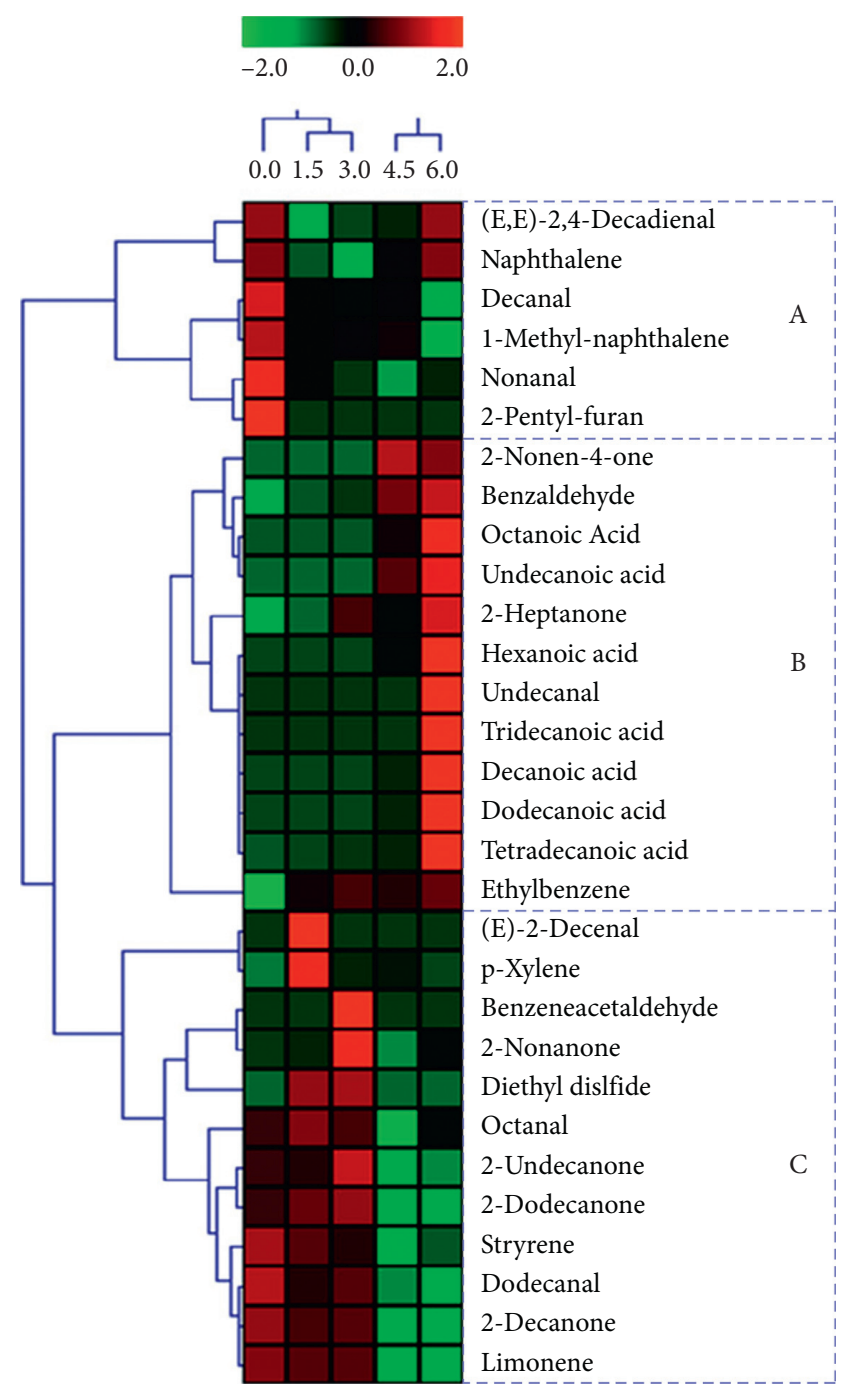

FIGURE 2: Heat map plots clusters of volatile compounds in yogurt fermented by $S$. thermophilus at different time points based on the OAVs. Green colors indicate that volatile compound levels were less than the mean levels during yogurt fermentation, while red colors indicate that volatile compound levels were higher than the mean levels.

decadienal, decanal, nonanal), two benzene derivatives (naphthalene, 1-methyl-naphalene), and 2-pentyl-furan. (E, E)-2,4-decadienal had the highest OAVs in most of yogurts located in this group. The B group contained 12 compounds, which showed high odor intensity in the end stage of fermentation including 7 acids (octanoic acid, undecanoic acid, hexanoic acid, tridecanoic acid, decanoic acid, dodecanoic acid, and tetradecanoic acid), 2 aldehydes (benzaldehyde and undecanal), 2 ketones (2-nonen-4-one, and 2-heptanone), and 1 benzene derivative (ethylbenzene). In this group, "rancid" was the important odor characteristic. The $\mathrm{C}$ group contained 12 compounds, which showed a high odor intensity in the $0-4.5 \mathrm{~h}$ yogurt samples including 4 aldehydes ((E)-2-decenal, benzeneacetaldehyde, octanal, and dodecanal), 4 ketones (2-nonanone, 2-undecanone, 2-dodecanone, and 2-decanone), 2 benzene derivatives ( $\mathrm{p}$-xylene and styrene), and 2 other compounds (diethyl disulfide and 
limonene). Octanal, dodecanal, and 2-undecanone had OAVs exceeding 1000, which had great influence on this group.

\section{Conclusions}

The volatile component profiles of yogurts had significant changes during the fermentation process by $S$. thermophilus. Ketones and hydrocarbons were the predominant volatile components at the early stage, with the extension of fermentation time acids becoming the predominant volatiles. "Fatty, green" provided by (E,E)-2,4-decadienal was the dominant odor in the whole yogurts fermentation process, and "rancid" odor intensity increased during fermentation. The heat map analyses could clearly differentiate the volatile compounds and OAVs of yogurts by $S$. thermophilus fermentation at different time points.

\section{Data Availability}

The data used to support the findings of this study are included within the article.

\section{Conflicts of Interest}

The authors declare that there are no conflicts of interest regarding the publication of this paper.

\section{Acknowledgments}

This study was funded by the National Key R\&D Program of China and the Ministry of Science and Technology of the People's Republic of China (2016YFD0401100).

\section{References}

[1] A. Saint-Eve, C. Lévy, N. Martin, and I. Souchon, "Influence of proteins on the perception of flavored stirred yogurts," Journal of Dairy Science, vol. 89, no. 3, pp. 922-933, 2006.

[2] H. Cheng, "Volatile flavor compounds in yogurt: a review," Critical Reviews in Food Science and Nutrition, vol. 50, no. 10, pp. 938-950, 2010.

[3] C. Chen, S. Zhao, G. Hao, H. Yu, H. Tian, and G. Zhao, "Role of lactic acid bacteria on the yogurt flavour: a review," International Journal of Food Properties, vol. 20, pp. 316-330, 2017.

[4] W. Routray and H. N. Mishra, "Scientific and technical aspects of yogurt aroma and taste: a review," Comprehensive Reviews in Food Science and Food Safety, vol. 10, no. 4, pp. 208-220, 2011.

[5] V. M. Marshall, "Starter cultures for milk fermentation and their characteristics," International Journal of Dairy Technology, vol. 46, no. 2, pp. 49-56, 1993.

[6] A. Y. Tamime and R. K. Robinson, Yoghurt: Science and Technology, Woodhead Publishing Ltd, Washington, DC, USA, 3rd edition, 2007.

[7] G. Rysstad and R. K. Abrahamsen, "Formation of volatile aroma compounds and carbon dioxide in yogurt starter grown in cows' and goats' milk," Journal of Dairy Research, vol. 54, no. 2, pp. 257-266, 1987.

[8] T. Erkaya and M. Şengül, "Comparison of volatile compounds in yoghurts made from cows', buffaloes', ewes' and goats' milks," International Journal of Dairy Technology, vol. 64, no. 2, pp. 240-246, 2011.

[9] Z. Güler and A. C. Gürsoy-Balcı, "Evaluation of volatile compounds and free fatty acids in set types yogurts made of ewes', goats' milk and their mixture using two different commercial starter cultures during refrigerated storage," Food Chemistry, vol. 127, no. 3, pp. 1065-1071, 2011.

[10] L. Zhao, R. Feng, F. Ren, and X. Mao, “Addition of buttermilk improves the flavor and volatile compound profiles of low-fat yogurt," Lebensmittel-Wissenschaft \& Technologie, vol. 98, pp. 9-17, 2018.

[11] T. Dan, D. Wang, R. L. Jin, H. P. Zhang, T. T. Zhou, and T. S. Sun, "Characterization of volatile compounds in fermented milk using solid-phase microextraction methods coupled with gas chromatography-mass spectrometry," Journal of Dairy Science, vol. 100, pp. 2488-2500, 2016.

[12] A. E. M. Boelrijk, C. de Jong, and G. Smit, Flavour Generation in Dairy Products Dairy Processing, G. Smith, Ed., pp. 128153, Woodhead Publishing, Cambridge, UK, 2003.

[13] J. Riener, F. Noci, D. A. Cronin, D. J. Morgan, and J. G. Lyng, "Characterisation of volatile compounds generated in milk by high intensity ultrasound," International Dairy Journal, vol. 19, no. 4, pp. 269-272, 2009.

[14] C. I. Vénica, I. V. Wolf, C. V. Bergamini, and M. C. Perotti, "Influence of lactose hydrolysis on galacto-oligosaccharides, lactose, volatile profile and physicochemical parameters of different yogurt varieties," Journal of the Science of Food and Agriculture, vol. 96, no. 15, pp. 4929-4939, 2016.

[15] R. Imhof, H. Glättli, and J. O. Bosset, "Volatile organic compounds produced by Thermophilic and Mesophilic single strain dairy starter cultures," LWT-Food Science and Technology, vol. 28, no. 1, pp. 78-86, 1995.

[16] J. Wang, Z. Xing, W. Tang, Y. Zheng, and Y. Wang, "Isolation, identification, and potential probiotic characterization of one Lactococcus from kefir grain," Food Science and Biotechnology, vol. 24, no. 5, pp. 1775-1780, 2015.

[17] P. A. Vazquez-Landaverde, G. Velazquez, J. A. Torres, and M. C. Qian, "Quantitative Determination of Thermally Derived Off-Flavor Compounds in milk using solid-phase microextraction and gas chromatography," Journal of Dairy Science, vol. 88, no. 11, pp. 3764-3772, 2005.

[18] P. A. Vazquez-Landaverde, J. A. Torres, and M. C. Qian, "Quantification of trace volatile sulfur compounds in milk by solid-phase microextraction and gas chromatography-pulsed flame photometric detection," Journal of Dairy Science, vol. 89, no. 8, pp. 2919-2927, 2006.

[19] Y. Karagül-yüceer, M. A. Drake, and K. R. Cadwallader, "Evaluation of the character impact odorants in skim milk powder by sensory studies on model mixtures," Journal of Sensory Studies, vol. 19, no. 1, pp. 1-13, 2004.

[20] Y. Li, L. Zhang, and W. Wang, "Formation of aldehyde and ketone compounds during production and storage of milk powder," Molecules, vol. 17, no. 8, pp. 9900-9911, 2012.

[21] R. Attai, "Quantification of volatile compounds in goat milk Jack cheese using static headspace gas chromatography," Journal of Dairy Science, vol. 92, pp. 2435-2443, 2009.

[22] J. Kubícková and W. Grosch, "Quantification of potent odorants in camembert cheese and calculation of their odour activity values," International Dairy Journal, vol. 8, pp. 17-23, 1998.

[23] M. Preininger and W. Grosch, "Evaluation of key odorants of the neutral volatiles of Emmentaler cheese by the calculation of odour activity values," LWT-Food Science and Technology, vol. 27, no. 3, pp. 237-244, 1994. 
[24] H. Tian, Y. Shi, Y. Zhang, H. Yu, H. Mu, and C. Chen, "Screening of aroma-producing lactic acid bacteria and their application in improving the aromatic profile of yogurt," Journal of Food Biochemistry, vol. 43, no. 10, p. e12837, 2019.

[25] G. A. Burdock, Fenaroli's Handbook of Flavor Ingredients, Taylor and Francis Group, London, UK, 6th edition, 2009.

[26] W. Wu, N.-p. Tao, and S.-q. Gu, "Characterization of the key odor-active compounds in steamed meat of Coilia ectenes from Yangtze River by GC-MS-O," European Food Research and Technology, vol. 238, no. 2, pp. 237-245, 2014.

[27] M. H. Tunick, "Analyzing volatile compounds in dairy products," Journal of the Science of Food and Agriculture, vol. 94, no. 9, pp. 1701-1705, 2014.

[28] G. Smit, B. A. Smit, and W. J. M. Engels, "Flavour formation by lactic acid bacteria and biochemical flavour profiling of cheese products," FEMS Microbiology Reviews, vol. 29, no. 3, pp. 591-610, 2005.

[29] L. Marilley and M. G. Casey, "Flavours of cheese products: metabolic pathways, analytical tools and identification of producing strains," International Journal of Food Microbiology, vol. 90, no. 2, pp. 139-159, 2004.

[30] H. E. Nursten, "The flavour of milk and dairy products: I. Milk of different kinds, milk powder, butter and cream," International Journal of Dairy Technology, vol. 50, no. 2, pp. 48-56, 1997.

[31] Y. F. Collins, P. L. H. McSweeney, and M. G. Wilkinson, "Lipolysis and free fatty acid catabolism in cheese: a review of current knowledge," International Dairy Journal, vol. 13, no. 11, pp. 841-866, 2003.

[32] T. F. O’Callaghan, D. T. Mannion, D. Hennessy et al., "Effect of pasture versus indoor feeding systems on quality characteristics, nutritional composition, and sensory and volatile properties of full-fat Cheddar cheese," Journal of Dairy Science, vol. 100, no. 8, pp. 6053-6073, 2017.

[33] S. Ozturkoglu-Budak, A. Gursoy, D. P. Aykas et al., "Volatile compound profiling of Turkish Divle Cave cheese during production and ripening," J. Dairy Sci. vol. 99, pp. 1-12, 2016.

[34] J. Pereda, D. P. Jaramillo, J. M. Quevedo, V. Ferragut, B. Guamis, and A. J. Trujillo, "Characterization of volatile compounds in ultra-high-pressure homogenized milk," International Dairy Journal, vol. 18, no. 8, pp. 826-834, 2008.

[35] H. S. Lam and A. Proctor, "Milled rice oxidation volatiles and odor development," Journal of Food Science, vol. 68, no. 9, pp. 2676-2681, 2003.

[36] L. Ning, Z. Fu-Ping, C. Hai-Tao et al., "Identification of volatile components in Chinese Sinkiang fermented camel milk using SAFE, SDE, and HS-SPME-GC/MS," Food Chemistry, vol. 129, no. 3, pp. 1242-1252, 2011.

[37] P. M. G. Curioni and J. O. Bosset, "Key odorants in various cheese types as determined by gas chromatography-olfactometry," International Dairy Journal, vol. 12, no. 12, pp. 959-984, 2002. 